Marquette University

e-Publications@Marquette

College of Education Faculty Research and

Publications

Education, College of

11-1-2009

\title{
Behavior Problems in Toddlers With and Without Developmental Delays: Comparison of Treatment Outcomes
}

\author{
Casey A. Holtz \\ Marquette University \\ Jennifer M. Carrasco \\ Marquette University \\ Ryan Mattek \\ Marquette University \\ Robert A. Fox \\ Marquette University, robert.fox@marquette.edu
}

Accepted version. Child and Family Behavior Therapy, Vol. 31, No. 4 (November 2009): 292-311.

DOI. (C) 2009 Taylor \& Francis (Routledge). Used with permission. 


\title{
Behavior Problems in Toddlers with and without Developmental Delays: Comparison of Treatment Outcomes
}

\author{
Casey A. Holtz \\ Department of Counseling and Educational Psychology \\ College of Education, Marquette University \\ Milwaukee WI \\ Jennifer M. Carrasco \\ Department of Counseling and Educational Psychology \\ College of Education, Marquette University \\ Milwaukee WI \\ Ryan J. Mattek \\ Department of Counseling and Educational Psychology \\ College of Education, Marquette University \\ Milwaukee WI \\ Robert A. Fox \\ Department of Counseling and Educational Psychology \\ College of Education, Marquette University \\ Milwaukee WI
}


NOT THE PUBLISHED VERSION; this is the author's final, peer-reviewed manuscript. The published version may be accessed by following the link in the citation at the bottom of the page.

\title{
Footnote:
}

Casey A. Holtz, M.A., Jennifer M. Carrasco, M.A., Ryan J. Mattek, and Robert A. Fox, Ph.D. Department of Counseling and Educational Psychology, College of Education, Marquette University, Milwaukee WI.

This research was supported in part by grants from the Assurant Health Foundation, Charles D. Jacobus Family Foundation, Exchange Club, and United Way. The authors acknowledge the support of Penfield Children's Center, the Birth-to-Three Agency that served as the site for this study and the graduate students who provided mental health services for the toddlers and their families.

Correspondence concerning this article should be addressed to Casey A. Holtz, Marquette University, Department of Counseling and Educational Psychology, College of Education, Schroeder Complex, P. O. Box 1881, Milwaukee WI 53201-1881. E-mail: casey.holtz@marquette.edu; Phone: 414915-8388.

\begin{abstract}
The purpose of this study was to examine the effectiveness of an inhome parent management program for toddlers with behavior problems and developmental delays by comparing outcomes for a group of toddlers with developmental delays $(n=27)$ and a group of toddlers without developmental delays $(n=27)$. The majority of children lived in single parent, low-income homes. Results suggested that the parent management program was equally effective for children with and without developmental delays. Parents from both groups reported clinically significant improvement in their children's behavior and parenting practices. Clinical implications regarding the importance of these findings for improving outcomes for toddlers with behavior problems and developmental delays living in poverty were discussed.
\end{abstract}

KEY WORDS: toddlers, developmental delay, behavior problems, treatment outcomes, low-income families

\section{Behavior Problems in Toddlers with and without Developmental Delays: Comparison of Treatment Outcomes}

Behavior problems are common in toddlers and include aggression, destructiveness, self-injury, temper tantrums, hyperactivity, and noncompliance (Roberts, Mazzucchelli, Taylor, \& Reid, 2003). While some behavior problems are expected to occur as a part of young children's normal development, when they escalate sufficiently in intensity and frequency, behavior problems can interfere with the child's development and cause significant distress for caregivers (Eyberg, Boggs, \& Rodriguez, 1992). Behavior problems have been shown to adversely affect a young child's interpersonal 
relationships (Greene \& Doyle, 1999), their development of social skills (Mendez, Fantuzoo \& Ciccetti, 2002) and communication ability (Sigafoos, 2000), and future academic achievement (Neilson \& McEvoy, 2004). The disruptive nature of early behavior problems also may result in child expulsion from day care or other community settings (Roberts et al., 2003). Moreover, some behavior problems become severe enough to warrant a psychiatric diagnosis such as attention deficit hyperactivity disorder, separation anxiety disorder, conduct disorder, or oppositional defiant disorder (Keenan \& Wakschlag, 2002).

Research indicates an increased risk for behavior problems among children with developmental delays (Hudson et al., 2003). Feldman, Hancock, Rielly, Minnes, \& Cairns (2000) examined the prevalence of challenging behaviors in a sample of 76 children with developmental delays and found that $42 \%$ of the children had clinically significant problems. Similarly, in a literature review, Roberts et al. (2003) found the prevalence of behavior problems in young children with delays ranged from 20 to $64 \%$. Children with both developmental delays and behavior problems also may be at an increased risk for negative long-term outcomes. These children typically require more medical and adjunctive services (e.g. speech therapy, physical therapy) than other children. Restricted participation or possible exclusion from such necessary supportive services due to behavior problems renders children with developmental delays at an everincreasing disadvantage relative to their typically developing peers (McDiarmid \& Bagner, 2005).

The negative consequences of significant behavior problems in early childhood are often not resolved through maturation alone. Once these problematic behaviors are established, they can persist into the elementary school years and adolescence (Campbell, 1995; Hudson et al., 2003), with the clear potential to develop into more serious disruptive or aggressive behavior (Bagner \& Eyberg, 2007; Feldman, et al., 2000; Roberts, Mazzucchelli, Studman, \& Sanders, 2006). Emotional and behavioral problems among children with intellectual and developmental disabilities are highly persistent over time (Einfeld et al., 2006). Hence, the toddler and preschool years present a unique window of opportunity for intervention to interrupt this developmental pathway and to prevent these challenging behaviors from becoming more resistant to change. 
A number of prevention and treatment programs for young children have emerged that focus on decreasing challenging behaviors (e.g., aggression, non-compliance, tantrums) and increasing pro-social behaviors (e.g., listening, sharing; see Eyberg, Nelson, \& Boggs, 2008 for a review). In these programs, cognitive and behavioral procedures designed to change parenting practices have significantly reduced early childhood behavior problems (Brinkmeyer \& Eyberg, 2003; Eyberg, Boggs, \& Algina, 1995; Nicholson, Brenner, \& Fox, 1999; Webster-Stratton, 1992). Interventions that specifically addressed young children with delays and behavior problems reported similar positive results (Gavida-Payne \& Hudson, 2002; McIntyre, 2008). For example, the Triple P-Positive Parenting Program (Sanders, 1999) was adapted by Sanders, Mazzucchelli, and Studman (2004, Stepping Stones Triple P-Program) to better meet the needs of families of children with delays and was shown to both improve children's behavior and positively alter parent-child interactions (Roberts et al., 2006). Similarly, an adapted version of the Incredible Years Parent Training Program (Webster-Stratton, 1992), a group-based program, was successful in reducing negative parent-child interactions and child behavior problems in children with developmental disabilities relative to a control group (McIntyre, 2008). In another study, McDiarmid and Bagner (2005) adapted Parent-Child Interaction Therapy (PCIT) to treat a 3-year-old male with both oppositional defiant disorder (ODD) and moderate mental retardation; after 14 treatment sessions, the child no longer met the criteria for ODD. Bagner and Eyberg (2007) evaluated the efficacy of PCIT, without adaptation, for children with comorbid ODD and mental retardation. Their results indicated that mothers interacted more positively with their children and reported significant improvements in their children's behavior after treatment.

Recent research has documented the positive effects of behavioral parent management programs tailored for children with developmental delays but continued study of treatment programs is warranted for several reasons. First, most studies have examined treatment effects for children in the preschool and elementary years (Brinkmeyer \& Eyberg, 2003; Eyberg et al., 1995; Webster-Stratton, 1992). Yet the genesis for behavior problems appears earlier in development, suggesting the need for prevention programs for families of even younger children. Second, research has often been conducted with well-educated, middle-income families. Relatively few 
studies have demonstrated results for parents with lower educational levels or for children living in poverty (Webster-Stratton, et al., 2001) despite the higher prevalence of childhood behavior problems in lowincome populations (Keenan \& Wakshlag, 2000). Finally, researchers have not directly compared treatment effects for children with and without developmental delays.

Due to the limited research in this area, it is unclear if early intervention is equally effective for children with and without developmental delay. Therefore, it is unclear whether it is necessary to design different treatment strategies or programs for children with developmental delays. The purpose of this study was to compare the outcomes of an evidenced-based parent management program for children less than five years of age (Fox \& Nicholson, 2003) between children with behavior problems to children with both developmental delays and behavior problems. The effectiveness of the treatment program was examined using a home-based, individualized program delivery system among mostly single-parent, low-educated families living in poverty in unsafe areas of a large, urban, inner-city environment.

\section{Method}

\section{Participants}

Children were referred for behavior problems by their caregivers and from professional staff members at a large Birth-to-Three Program and from other agencies and health care professionals serving toddlers in an urban Midwestern city. Eligibility criteria for the study included: (a) an ambulatory child between the ages of 1 and 5 years; (b) parental report of concern regarding behavior problems such as noncompliance, serious tantrums, aggression, destructiveness, and high activity level; (c) child did not meet diagnostic criteria for a pervasive developmental disorder or have significant physical handicaps or serious medical conditions; and (d) family completed the treatment program with both pre- and post-test assessments. The first 27 referred children who met the eligibility criteria and had a developmental delay were enrolled in the study and placed in the delayed group. Developmental delay was defined as scoring at least $25 \%$ below chronological age (or corrected age for children 2 years of age and younger born premature) in one or more areas of 
development (e.g., speech, cognition, motor) using the Early Intervention Developmental Profile (Rogers \& D'Eugenio, 1981). The majority of the children in the delayed group were identified as having a speech delay as their primary concern $(n=25 ; 92 \%)$. Of these 25 children, $24 \%$ also had a significant cognitive delay. The remaining two children had both cognitive and motor delays. Concurrently, the first 27 referred children who met the eligibility criteria and did not have a developmental delay were enrolled in the study and placed in the non-delayed group. Demographic data for the children and their caregivers are shown by group in Table 1 . Statistical analyses did not identify any significant differences $(p>.05)$ between groups on any of these demographic variables.

\section{Measures}

A number of measures were utilized to evaluate parent and child variables. All of the measures were administered during the intake evaluation and again at the post-test evaluation that occurred following the final treatment session.

Early Intervention Developmental Profile (EIDP). The EIDP (Rogers \& D'Eugenio, 1981) is an infant and preschool assessment measure designed to provide a comprehensive description of a child's present functioning and to identify areas of delay. The EDIP is made up of 299 items divided into six scales which provide developmental norms in the following areas: perceptual/fine motor, cognition, language, social/emotional, self-care and gross motor development. Scores of $25 \%$ or more below chronological age level in one or more scales indicate a significant developmental delay that is required for enrollment in Birth-to-Three services. The six scales of the EIDP demonstrate moderate to strong correlations with other standardized evaluation instruments including the mental $(.80-.96)$ and motor (.66 - .95) scales of the Bayley Scales of Infant Development (Bayley, 1993) and the Vineland Social Maturity Scale (.77 - .93; Sparrow, Balla, \& Cicchetti, 1984). Test-retest correlations at 3 to 6 months were: language $=.93$; social/emotional $=.98$; self-care $=.98$; cognition $=.97 ;$ perceptual/fine motor $=.98$ and; gross motor $=.97$.

Eyberg Child Behavior Inventory (ECBI). The ECBI (Eyberg \& Pincus, 1999) is a 36 -item inventory that measures behavior problems common in children ages 2 to 16 -years-old (e.g., non-compliance, aggression, destructiveness). Caregivers rated the frequency of each 
behavior problem on a scale from 1 (never) to 7 (always), resulting in an intensity score (range $=36-252$ ). Parents also identified if each behavior was considered a current problem (yes/no) resulting in a total problem score (range=0-36). Eyberg and Pincus (1999) established a T-score of greater than 60 on the ECBI intensity and problem scales as a cutoff point for identifying children with clinically significant levels of behavior. Internal consistency has been reported for both the intensity and the problem scales (.95 and .93, respectively; Burns \& Patterson, 1990); and studies have found that the ECBI has adequate test-retest reliability ranging from .86-.88 (Eyberg \& Pincus, 1999). The ECBI has been shown to discriminate between problem and non-problem children (Weis, Lovejoy, \& Lundahl, 2004). In addition, research has demonstrated the ECBI to be sensitive to behavior change from pre-test to post-test in studies on behavioral interventions with high-risk families enrolled in a Head Start program (Webster-Stratton et al., 2001) and with clinically referred children (Eyberg et al., 2001).

Parent Behavior Checklist (PBC). The PBC (Fox, 1994) is a 32item rating scale designed to measure the behaviors and expectations of parents of young children between the ages of 1 and 5 years. The PBC consists of three empirically derived scales: Expectations, 12 items that measure parents' developmental expectations (e.g. "my child should be quiet when I am on the phone"); Discipline, 10 items that assess parental responses to children's problem behaviors (e.g. "I would spank my child in public for bad behavior"); and Nurturing, 10 items that measure specific parent behaviors that promote a child's psychological growth (e.g. "I praise my child for learning new things"). Items are rated using a 4-point frequency scale (4 = almost always/always, 3 = frequently, 2 = sometimes, and 1 = almost never/never). The range of total scores for each subscale are: Expectations (12-48) with higher scores indicating higher parental expectations; Discipline (10-40) with higher scores indicating more frequent use of verbal and corporal punishment (e.g. yelling or spanking); and Nurturing (10-40) with higher scores suggesting more frequent use of positive nurturing activities. The following coefficient alphas were reported for the PBC short form: Expectations $=.97$, Discipline $=.91$ and Nurturing $=.82$. Test-retest reliabilities for each of the three subscales were: Expectations $=.98$, Discipline $=.87$ and Nurturing $=.81$. The PBC successfully discriminates between parents 
of children of different chronological ages (Fox \& Bentley, 1992) and in one study, was shown to not be related to a social desirable response set (Peters \& Fox, 1993). The PBC's utility has been demonstrated with families of children with disabilities (Keller \& Fox, 2009; Tucker \& Fox, 1995 ) and significant emotional and behavioral problems (Nicholson, Fox, \& Johnson, 2005). Finally, the PBC has been used as an outcome measure for treatment programs involving parents of young children (Nicholson, Anderson, Fox, \& Brenner, 2002; Nicholson et al., 1999).

Direct Observation of Parent-Child Interactions. A direct observation assessment based on the work of Crawley and Spiker (1983) was used to assess the quality of parent and child interactions at intake and post-test. Clinicians were initially trained to reliably observe and rate parent-child interactions using videotaped sessions of parent-child dyads playing together. Parent's and children's behaviors were both operationally defined, and clinicians were trained using videotaped parent-child interactions until their agreement rate consistently achieved a minimum $80 \%$ with the clinic's established observational data for these videotaped interactions.. As part of the intake evaluation, parents were instructed to play with their children while the clinician rated their interactions (i.e., $1=$ never, 2 = seldom, 3 = average, 4 = usually, $5=$ always) on five dimensions of the child's behavior (i.e., positive affect, negative affect, interest in play, initiates interactions, socially responsive), and six dimensions of the parent's behavior (i.e., parent directs play, parent lets child direct play, sensitivity to child, expectations for child, discipline - sets appropriate limits, and reciprocity). Separate total scores were computed for the five combined dimensions of child behavior and the six combined ratings of parent behavior. Coefficient alphas have been reported for the total child scores (.85) and the total parent scores (.83) (Fox, Keller, Grede, \& Bartosz, 2007). For this sample, internal consistency scores were .79 for the total parent scores and .77 for the total child scores. Some cases were observed and rated by the treating clinician, which may have interjected bias into the results. However, two independent raters completed the parent and child ratings as a measure of inter-rater reliability for approximately $30 \%$ of the observations. Correlations were computed between the total scores obtained by each clinician, yielding significant inter-rater reliability coefficients for the total parent (.77) and child (.72) scores. 
Following the play assessment, parents were told to give their child five simple requests (e.g., pick up the toy, come here) to assess their child's compliance. After recording the number of parental requests and the child's compliance (i.e., yes or no), a compliance percentage score was computed. For approximately $30 \%$ of the observations in this sample, two clinicians independently completed the compliance assessment. Inter-rater reliability for the child compliance rate (i.e., child compliance/parent requests) was .80 .

Kiddie Schedule for Affective Disorders and Schizophrenia for School-Aged Children (K-SADS-PL). The K-SADS-PL (Kaufman et al., 1997) was completed before and after the treatment program to determine whether the child met the diagnostic criteria for a psychiatric disorder included in the Diagnostic and Statistical Manual of Mental Disorders (DSM-IV-TR; APA, 2000). The K-SADS-PL is a semistructured parent interview designed to assess current and past episodes of psychopathology in children. Probes are used to elicit the information necessary to score each item. Items assessing the presence and intensity of diagnostic symptoms are scored using a 0-3 point rating scale. A score of 0 indicates no information is available, a score of 1 suggests the symptom is not present, a score of 2 indicates subthreshold levels of symptomatology, and a score of 3 represents threshold criteria. Items related to pervasiveness and duration of symptomology are rated on a 0-2 point rating scale on which 0 implies no information, 1 implies the symptom is not present, and 2 implies the symptom is present. Diagnoses are derived from a total score on the $K$-SADS-PL for each relevant diagnosis (e.g., Oppositional Defiant Disorder, Conduct Disorder).

Parent-Child Relationship Scale. This scale provides a qualitative global assessment of the parent and child relationship on a scale of 0100 with five behavioral anchors (Poor, Below Average, Average, Good, and Exceptional) at 20-point intervals (Fox \& Nicholson, 2003). For example, scores suggestive of a good relationship (e.g., thoughtful interactions, typically appropriate parental expectations, parent responsiveness, appropriate limit setting, and limited use verbal or corporal punishment) range from 60-80. The child's clinician determined the Parent-Child Relationship Scale's global score after a careful review of all assessment findings including direct observation and the scores from parent self-report measures. 
NOT THE PUBLISHED VERSION; this is the author's final, peer-reviewed manuscript. The published version may be accessed by following the link in the citation at the bottom of the page.

Family Satisfaction Survey. A 7-item survey was used to assess caregiver satisfaction with the treatment services. Using a 7-point Likert rating scale, caregivers are asked to rate: the quality of services received $(1=$ poor to $7=$ excellent), how the services contributed to their child's improvement ( $1=$ not at all to $7=a$ lot), how the clinic helped them improve how they managed their children $(1=$ not at all to $7=a l o t$ ), if caregivers would use the clinic again if needed ( $1=n o$, definitely not to 2 = yes, definitely), the current status of child's referral concern ( $1=$ considerably worse to $7=$ greatly improved), if caregivers would recommend the clinic to others $(1=$ no, definitely not to 7 = yes, definitely), and the caregiver's confidence in managing their children's behavior in the future $(1=$ not at all confident to $7=$ very confident). For the present sample, the internal consistency for these seven items was $r=.72$.

\section{Intervention}

Parent Management Training. The treatment program was adapted from the Parenting Young Children Program (Fox \& Nicholson, 2003) with an introductory child-led play component added to the treatment protocol. Treatment sessions were scheduled weekly in the children's homes and lasted approximately 60 to 90 minutes. Families in the delayed group averaged 12 treatment sessions $(S D=4.65$ ) over 4.31 months $(S D=2.20)$ and families in the non-delayed group averaged 12.89 sessions $(S D=5.26$ ) over 5.44 months $(S D=2.20)$. Treatment included five components: (a) enriching the parent/child relationship through child-led play; (b) helping the parents learn to thoughtfully interact with their child rather than emotionally overreact to their child's behavior; (c) helping the parents learn and maintain appropriate developmental expectations for their child; (d) using techniques such as positive reinforcement, establishing home routines, and giving good instructions to strengthen their child's prosocial behaviors; and (e) employing limit-setting strategies such as redirection, ignoring, response cost, and time-out (i.e., placement of child in a safe area away from direct reinforcement) to reduce their child's challenging behaviors. For example, a common time-out location was a safe bedroom with a gate placed across the door so the child could look out into the rest of the home. Parents were carefully instructed to not interact with their child while in time-out. 
Each treatment strategy was explained to the caregiver and directly modeled by the clinician. During treatment sessions, parents also practiced each strategy with their children and received direct insession feedback from the clinician. Following modeling and the feedback sessions, a treatment plan that tailored the procedures to each individual child and parent was developed. All materials needed to implement the treatment plan were provided by the clinician (e.g., parent handouts, edible reinforcers, stickers, door gates for time-out). In subsequent sessions, treatment strategies were fine-tuned as necessary to meet the unique needs of each child, their caregivers, and the home setting. The weekly behavior plan would include strategies directly related to the primary treatment components but those strategies might differ for each individual family, based on their individual strengths and limitations and their salient concerns. For example, the behavior plan may include: (1) play with Steve for 10 minutes right before supper; (2) give Steve five simple requests during the day such as "pick up the toy" or "come here" and provide an immediate edible reward and praise each time; and (3) use a one minute time-out when Steve hits his younger sister.

\section{Procedures}

Institutional Review Board approval for this study was provided by an urban private university. Parents referred for this study provided consent for themselves and their children to participate. Parents were informed both verbally and in writing regarding the research methodology and requirements. Parents were also informed about the intervention procedures and were told that they could withdraw from the study at any time without affecting their child's other clinical services. Once parents consented, an intake evaluation was completed that included the collection of the study's pre-test measures.

All treatment services were provided in the children's homes. As most of these homes were located in high-crime neighborhoods, clinicians often travelled in pairs to provide treatment services, were provided appropriate training in safety procedures (e.g., declining invitations into the house by individuals other than the child's guardian, continually being aware of one's surroundings, carrying limited personal money), and had access to an on-call supervisor at all times in the event a clinician required assistance (e.g., depressed/suicidal caregiver, evidence of child abuse). Treatment 
services were provided by clinicians who had successfully completed an intensive training program and who met specific treatment adherence criteria. Clinicians were observed by their supervisor and were allowed increased treatment independence as they demonstrated sensitivity to working with a diverse population of families living in poverty, effectively and accurately explained and modeled treatment techniques, and provided appropriate feedback to parents. Supervisors further monitored clinician adherence to the treatment protocol through case review during weekly supervision (group and individual). Caregivers were asked to document their use of treatment strategies each day between the weekly in-home treatment sessions by marking whether or not they followed the treatment plan developed specifically for their child. Caregivers who completed this documentation and submitted it to the clinician at the next session were provided a $\$ 5 \mathrm{gift}$ certificate to use at a local grocery store. Treatment services were terminated when the program was completed and post-test measures were obtained. Families were encouraged to contact the clinician if future concerns about their children arose.

\section{Results}

Separate repeated measures analyses of variance were used to assess between-group (i.e. delayed or non-delayed) and within-group (i.e., pre- and post-treatment) intervention effects for the children and parents (see Table 2). Where significant interaction or main effects for group or time were found, univariate $F$-tests were computed to determine the source of the significance. Group means were used to substitute for missing data. There were no significant differences $(p>$ .05) between groups on pre-treatment measures of child behavior problems (i.e., intensity and problem), the parent-child relationship, and parental nurturing, expectations, or discipline.

\section{Child Behavior}

Parent report. ECBI ratings of children's behavior problems indicated a significant time effect $\left(F_{2,51}=14.86, p<.01, \eta^{2}=.40\right)$ with no significant group or interaction effects. Following treatment, children's problem behaviors decreased in intensity $\left(F_{1,52}=12.53\right.$, $\left.p<.01, \eta^{2}=.19\right)$ and were considered less problematic for parents $\left(F_{1,52}=25.28, p<.01, \eta^{2}=.33\right)$ in both the delayed and non-delayed groups (see Table 2 ).

Child \& Family Behavior Therapy, Vol. 31, No. 4 (November 2009): pg. 292-311. DOI. This article is (C) The New Chaucer Society and permission has been granted for this version to appear in e-Publications@Marquette. The New Chaucer Society does not grant permission for this article to be further copied/distributed or hosted elsewhere without the express permission from The New Chaucer Society. 
Direct observation. Observation of child behavior during parentchild interactions in the home setting revealed a significant time effect $\left(F_{1,51}=3.98, p<.01, \eta^{2}=.07\right)$ with no significant group or interaction effects. Following treatment, child total behavior scores improved significantly. Contributing to this significant change, were improvements in four of the five ratings comprising this measure. Child positive affect increased $\left(F_{1,52}=33.06, p<.01, \eta^{2}=.39\right)$ and negative affect decreased $\left(F_{1,52}=28.66, p<.01, \eta^{2}=.35\right)$ for both groups. In addition, the child's social responsiveness $\left(F_{1,52}=28.66, p\right.$ $\left.<.01, \eta^{2}=.35\right)$ and interest in play increased $\left(F_{1,52}=7.56, p<.01, \eta^{2}\right.$ $=.13$ ) from pre-test to post-test. No significant change in child initiation of interactions was identified.

\section{Parent Behavior}

Parent report. Parent ratings on the PBC revealed a significant main effect for time $\left(F_{3,50}=5.75, p<.01, \eta^{2}=.26\right)$ with no significant group or interaction effects. Following intervention, parental expectations increased $\left(F_{1,52}=11.89, p<.01, \eta^{2}=.19\right)$ and parent use of verbal and corporal punishment decreased $\left(F_{1,52}=4.20, p\right.$ $\left.<.05, \eta^{2}=.08\right)$ in both groups. Nurturing scores did not change.

Direct observation. Observation of parent-child interactions in the home at pre- and post-treatment revealed significant main time effect for parent factors $\left(F_{1,51}=26.74, p<.01, \eta^{2}=.34\right)$ with no significant group or interaction effects. Following treatment, parent total scores improved significantly. Contributing to this significant change were improvements in all six ratings that comprise this measure. Both groups decreased parent-led play $\left(F_{1,52}=12.76, p\right.$ $\left.<.01, \eta^{2}=.2\right)$ and increased child-led play $\left(F_{1,52}=23.10, p<.01, \eta^{2}=\right.$ $.31)$. Parent sensitivity increased $\left(F_{1,52}=18.34, p<.01, \eta^{2}=.26\right)$ as did parental expectations $\left(F_{1,52}=23.05, p<.01, \eta 2=.31\right)$. Parent use of appropriate limit setting increased $\left(F 1,52=12.57, p<.01, \eta^{2}=\right.$ $.02)$ for both groups. Also, the parent-child interactions increased in reciprocity $\left(F_{1,52}=28.84, p<.01, \eta^{2}=.36\right)$. Overall, both groups improved on the Parent-Child Relationship scale $\left(F_{1,52}=62.5, p<.01\right.$, $\eta^{2}=.54$ ) with no significant group or interaction effects (see Table 2 ). 
NOT THE PUBLISHED VERSION; this is the author's final, peer-reviewed manuscript. The published version may be accessed by following the link in the citation at the bottom of the page.

\section{Clinical Significance}

Reliable Change Index. Clinical significance was determined by the Reliable Change Index (RCI; Jacobson \& Truax, 1991) using a minimum RCI value of 1.96 to indicate reliable change. Table 3 shows the percentage of children whose behavior reliably changed in the positive direction. Chi-square analyses were computed to identify significant differences between groups. Significantly more parents from the non-delayed group ( $n=13,48 \%$ ) reported reliable reductions in verbal and corporal discipline as measured by the PBC's discipline subscale when compared to the non-delayed group $(n=6,22 \%)$, $X^{2}(1,54)=3.98, p<.05$. Significantly more parents from the delayed group ( $n=20,75 \%$ ) had clinically significant improvements in the parent-child relationship when compared to the non-delayed group ( $n$ $=8,30 \%), X^{2}(1,54)=10.68, p<.01$. No significant between group relationships were found on the ECBI (intensity and problem scales), PBC (nurturing and expectation scales), or direct observation measures.

Psychiatric Diagnosis. Nineteen children in the delayed group were diagnosed with a psychiatric disorder at intake through direct observation, parent report, and the use of the $K-S A D S-P L$. None of the children in this sample were diagnosed with multiple psychiatric disorders. The most common primary diagnosis was ODD (48\%). At post-treatment, 15 of these 19 children (79\%) no longer met the diagnostic criteria $\left(X^{2}{ }_{1,23}=9.78, p<.01\right)$. Twenty-one children in the non-delayed group were diagnosed at pre-treatment. The most common diagnosis was again ODD (67\%). At post-treatment, 16 of these children (76\%) no longer met diagnostic criteria postintervention $\left(x_{1,26}^{2}=9.85, p<.01\right)$. In sum, $78 \%(n=31)$ of all children diagnosed with a psychiatric disorder at pre-treatment no longer met criteria for psychiatric diagnosis at post-treatment $\left(X_{1,49}^{2}=\right.$ $19.61, p<.01)$. No significant differences were found between the numbers of children with pre- or post-treatment diagnoses based on group membership.

ECBI: Clinical Level of Behavior. Eyberg and Pincus (1999) recommended a $t$-score of 60 as a cutoff score to determine if the child's scores on the ECBI's intensity and problems scales were clinically significant. Thirteen children in the delayed group were rated above the clinical cut-off for intensity of behavior at intake and 8 were rated at this level at post-treatment $\left(x^{2}{ }_{1,26}=7.05, p<.01\right)$. Seventeen 
children in the no delay group were rated above clinical cut-off for intensity at intake and 15 were rated at this level at post-treatment $\left(X^{2}{ }_{1,26}=4.20, p<.05\right)$. Chi-square analyses examining the relationship between pre- and post-test scores between groups indicated significantly more children in the no delay group were rated above clinical cut-off for intensity of behavior at pre- and at post-treatment $\left(x^{2}{ }_{1,53}=3.71, p=.05\right)$. Twenty-seven children in the no delay group were rated as clinically problematic at pre-treatment and 15 were rated at this level at post-treatment $\left(x^{2}{ }_{1,26}=3.86, p<.05\right)$. Similarly, 27 children in the delay group were rated as clinically problematic at pre-treatment and 11 were rated at this level at post-treatment $\left(x^{2} 1,26\right.$ $=4.54, \mathrm{p}<.05)$. There were no significant between group relationships.

\section{Parent Satisfaction}

Forty-nine parents (91\%) completed the parent satisfaction questionnaire. Parents rated the quality of the program highly ( $M=$ 6.76 ; $S D=.59$ ), indicating that they viewed the services received as good to excellent. There were no significant differences between parents of children with or without developmental delays on the satisfaction measure. Parents reported that the program improved their child's behavior $(M=6.20 ; S D=.84)$, helped them learn new strategies to manage their child's behavior $(M=6.47 ; S D=.84)$ and increased their confidence in their ability to manage their child's behavior in the future $(M=6.02 ; S D=1.16)$. Parents also indicated that they would encourage others to contact the study's personnel to address their child's behavior problems.

\section{Discussion}

This study investigated the effectiveness of a community-based, parent management program on delayed and non-delayed toddlers with behavior problems, most of who were living in poverty. Results indicated that children with and without developmental delays experienced similar reductions challenging behavior, enrichment in the parent-child relationship, and improvement in parenting behavior and skills. Although average scores for the non- delayed group suggested the intensity of many children's challenging behaviors remained at a clinical level at post-test, children's challenging behaviors were less intense and problematic after treatment. Importantly, of the 40 
children who met the criteria for a psychiatric disorder diagnosis at pre-test, 31 no longer met the same criteria at post-test. Parent-child interactions improved over time as children in the program demonstrated increased positive affect and responded more to their parents. Parents became more sensitive to their child's cues and set appropriate limits on their challenging behaviors, resulting in decreased use of verbal and corporal punishment and an improvement in their ability to establish appropriate expectations. One intention of this treatment program was to teach parents developmentally appropriate strategies to interact with their children through an adjustment of their expectations and modeling of parenting strategies such as play, positive reinforcement, and limit setting. This study suggested that the treatment protocol effectively educated parents regarding developmentally appropriate practices, thus enabling them to improve their interaction with their children, which led to positive outcomes for both delayed and non-delayed groups.

Not only do the results support the positive findings of previous research on behavioral family interventions for young children with behavior problems and disabilities (McDiarmid \& Bagner, 2005; Roberts et al., 2006), but they also expand the focus of research to include toddlers. Early intervention is critical because childhood behavior problems can emerge very early in a child's development soon after a child begins to walk and talk. Further, research suggests that parents of toddlers experience significant levels of stress and frustration, peaking at age 3 years, due to concerns regarding difficulties with behavior management and discipline (e.g., Bayer, Hiscock, Ukoumunne, Price, and Wake, 2008; Jenkins, Bax, and Hart, 1980; Richman, Stevenson, \& Graham, 1982). Treatments for toddlers can target challenging behaviors before they become embedded and more difficult to manage, and treatment may be especially critical for children with disabilities because they are at an increased risk for behavior problems and related negative outcomes. This is also a critical time to intervene because the parents are motivated to participate and engage in treatment, preventing them from inadvertently reinforcing the challenging behaviors and from falling into poor parenting habits. The results of this study suggested that early treatment was effective and therefore should begin as early as possible to prevent the escalation of challenging behaviors to later, more severe, and possibly chronic behavior problems. However, the 
absence of a long-term follow-up prevents us from identifying whether the benefits of the program are maintained over time. We are presently engaged in a follow-up study that will essentially repeat the study's outcome measures one to three years after treatment completion.

This study also demonstrated that parent management training is effective with single, low-educated parents living in poverty. Such findings are significant because poverty is pervasive risk factor (Qi \& Kaiser, 2003) that impacts many areas of a family's life such as parenting styles, child characteristics (e.g., attachment, cognition, temperament, social skills), and parent factors (e.g., stress, discipline, education level). In general, young children from low-income households are at an increased risk for developing behavior problems (Olson, Ceballo, \& Park, 2002). Further, there are indicators that caregivers of children with developmental delays experience higher stress levels (Rodriguez \& Murphy, 1997), and poverty may serve as an additional burden that increases the vulnerability of these children. Unfortunately, research shows that the risk factors experienced by families in poverty often make treatment difficult and may lead to poor attendance rates and high levels of attrition (Armbruster \& Kazdin, 1994). This treatment program was specifically designed to be sensitive to the issue of poverty. For example, clinicians conducted all of the treatment sessions in each family's home, scheduled visits at times convenient to the caregiver, made reminder phone calls to caregivers before sessions, and adapted treatment programs as necessary to meet the unique needs of the family and the home environment.

The results of this study are promising. However, due to the acute needs of the families referred to the community clinic, the researchers were unable to place families into a control group. While a wait-list control group would strengthen the findings of this study, it was quickly learned that this would not be reasonable given the significant difficulty experienced in initially engaging families and in maintaining them throughout the treatment program. Fox and Holtz (2008) reported a $57 \%$ treatment attrition rate for a similar population of children with developmental delays from low-income families, which is higher than the $33 \%$ reported in other treatment studies for families of children with developmental disabilities (Roberts et al., 2006) and the $50 \%$ rate for children from low-income families (Nicholson et al., 
1999). This high rate exemplifies the inherent challenges of providing mental health services to this population.

Therefore, it is important to acknowledge that the apparent effectiveness of the treatment program may be moderated or directly impacted by variables that were not directly measured or controlled in this study. For example, prior research suggested that factors including parental stress and psychopathology relate directly to parent perception of child behavior problems (Baker, Blacher, Crnic \& Edelbrock, 2002) and affect treatment outcomes for young children (Snell-Johns, Mendez, \& Smith, 2004). Therefore, the decline in child behavior problems reported by parents in this study may have been a result of decreased parental stress due to reasons other than the treatment program. Other factors such as daycare experiences, interactions with other caregivers, additional therapies (e.g., speech, occupational therapy), medical interventions, and child development or maturation may have also resulted in positive change in child behavior. These variables are important to consider but are difficult to control considering the complex systems involved in many children's lives. In fact, research designed to investigate predictors, mediators, and moderators of behavioral treatment programs outcomes has found inconsistent results (McMahon, Wells, \& Kotler, 2006). Therefore, while a better understanding of the multiple and interacting influences on the outcome of treatments for challenging behavior would enhance the understanding of full treatment effects, the findings of this study indicate that parents and toddlers, with and without developmental delays, from low-income populations can benefit from in-home parent management training.

\section{References}

American Psychological Association. (2000). Diagnostic and statistical manual of mental disorders (4th ed. text revision). Washington, D.C.: Author.

Armbruster, P. \& Kazdin, A. E. (1994). Attrition in child psychotherapy. In T.H. Ollendick \& R.J. Prinz (Eds.), Advances in Clinical Child Psychology (pp 81-108). New York: Plenum.

Bagner, D. M., \& Eyberg, S. M. (2007). Parent-child interaction therapy for disruptive behavior in children with mental retardation: A randomized controlled trial. Journal of Clinical Child and Adolescent Psychology, 36, 418-429.

Baker, B. L., Blacher, J., Crnic, K. A., \& Edelbrock, C. (2002). Behavior problems and parenting stress in families of three-year-old children 
with and without developmental delays. American Journal of Mental Retardation, 107, 433-444.Bayer, J. K., Hiscock, H., Ukoumunne, O. C., Price, A., \& Wake, M. (2008). Early childhood aetiology of mental health problems: A longitudinal population-based study. Journal of Child Psychology and Psychiatry, 49, 1166-1174.

Bayley, N. (1993). Bayley Scales of Infant Development, Second Edition. San Antonio, TX: The Psychological Corporation.

Brinkmeyer, M. Y., \& Eyberg, S. M. (2003). Parent-child interaction therapy for oppositional children. In A.E. Kazdin \& J.R. Weisz (Eds.). Evidenced-based psychotherapies for children and adolescents (pp.204-223). New York: Guilford.

Burns, G. L., \& Patterson, D. R. (1990). Conduct problem behaviors in a stratified random sample of children and adolescents: New standardization data on the Eyberg Child Behavior Inventory. Psychological Assessment, 2, 391-397.

Campbell, S. B. (1995). Behavior problems in preschool children: A review of recent research. Journal of Child Psychology \& Psychiatry, 36, 113149.

Crawley, S. B., \& Spiker, D. (1983). Mother-child interactions involving twoyear-olds with Down syndrome: A look at individual differences. Child Development, 54, 1312-1323.

Einfeld, S., Piccinin, A., Mackinnon, A., Hofer, S., Taffe, J., Gray, K., et al. (2006). Psychopathology in young people with intellectual disability. Journal of the American Medical Association, 296, 1981-1989.

Eyberg, S. M., Boggs, S., \& Algina, J. (1995). Parent-child interaction therapy: A psychosocial model for the treatment of children with conduct problem behavior and their parents. Psychopharmacology Bulletin, 31, 83-91.

Eyberg, S. M., Boggs, S. R., \& Rodriguez, C. M. (1992). Relationships between maternal parenting stress and child disruptive behavior. Child and Family Behavior Therapy, 14, 1-9.

Eyberg, S. M., Funderburk, B. W., Hembree-Kigin, T. L., McNeil, C. B., Quierdo, J. G., \& Hood, K. K. (2001). Parent-child interaction therapy with behavior problem children: One and two year maintenance of treatment effects in the family. Child and Family Behavioral Therapy, 23, 1-20.

Eyberg, S. M., Nelson, M. N., \& Boggs, S. R. (2008). Evidence-based psychological treatments for children and adolescents with disruptive behavior. Journal of Clinical Child and Adolescent Psychology, 37(1), 215-237.

Eyberg, S. M., \& Pincus, D. (1999). Eyberg Child Behavior Inventory and the Sutter-Eyberg Student Behavior Inventory-Revised. Lutz, FL: Psychological Assessment Resources, Inc.

Child \& Family Behavior Therapy, Vol. 31, No. 4 (November 2009): pg. 292-311. DOI. This article is (C) The New Chaucer Society and permission has been granted for this version to appear in e-Publications@Marquette. The New Chaucer Society does not grant permission for this article to be further copied/distributed or hosted elsewhere without the express permission from The New Chaucer Society. 
NOT THE PUBLISHED VERSION; this is the author's final, peer-reviewed manuscript. The published version may be accessed by following the link in the citation at the bottom of the page.

Feldman, M. A., Hancock, C. L., Rielly, N., Minnes, P., \& Cairns, C. (2000). Behavior problems in young children with or at risk for developmental delay. Journal of Child and Family Studies, 9 (2), 247-261.

Fox, R. A. (1994). Parent behavior checklist. Austin, TX: ProEd (Currently available from the author, Marquette University, School of Education, P.O. Box 1881, Milwaukee, WI 53201-1881; Email:robert.fox@marquette.edu).

Fox, R. A., \& Bentley, K. S. (1992). Validity of the Parenting Inventory: Young Children. Psychology in the Schools, 29, 101-107.

Fox, R. A., \& Holtz, C. A. (In Press). Treatment outcomes for toddlers with behavior problems and developmental delays from low-income families. Child and Adolescent Mental Health.

Fox, R. A., Keller, K. M., Grede, P. L., \& Bartosz, A. M. (2007). A mental health clinic for toddlers with developmental delays and behavior problems. Research in Developmental Disabilities, 28, 119-129.

Fox, R. A., \& Nicholson, B. C. (2003). Parenting young children: A facilitator's guide. Longmont, Colorado: Sopris West.

Gavidia-Payne, S., \& Hudson, A. (2002). Behavioral supports for parents of children with an intellectual disability and problem behaviours: An overview of the literature. Journal of Intellectual and Developmental Disability, 27, 31-55.

Greene, R. W., \& Doyle, A. E. (1999). Toward a transactional conceptualization of oppositional defiant disorder: Implications for assessment and treatment. Clinical Child and Family Psychology Review, 2, 129-148.

Hudson, A. M., Matthews, J. M., Gavidia-Payne, S. T., Cameron, C. A., Mildon, R. L., Radler, G. A., \& Nankervis, K. L. (2003). Evaluation of an intervention system for parents of children with intellectual disability and challenging behavior. Journal of Intellectual Disability Research, 47, 238-249.

Jacobson, N. S., \& Truax, P. (1991). Clinical significance: A statistical approach to defining meaningful change in psychotherapy research. Journal of Consulting and Clinical Psychology, 59(1), 12-19.

Jenkins, S., Bax, M., \& Hart, H. (1980). Behavior problems in preschool children. Journal of Child Psychology and Psychiatry, 21, 5-18.

Kaufman, J., Birmaher, B., Brent, D., Rao, U., Ryan, N., Flynn, C., \& Moreci, P. (1997). The Revised Schedule for Affective Disorders and Schizophrenia for School Aged Children: Present and Lifetime Version: Preliminary reliability and validity data. Journal of the American Academy of Child and Adolescent Psychiatry, 36, 980-988.

Keenan, K., \& Wakschlag, L. (2000). More than the terrible twos: The nature and severity of behavior problems in clinic-referred preschool children. Journal of Abnormal Child Psychology, 28, 33-46.

Child \& Family Behavior Therapy, Vol. 31, No. 4 (November 2009): pg. 292-311. DOI. This article is (c) The New Chaucer Society and permission has been granted for this version to appear in e-Publications@Marquette. The New Chaucer Society does not grant permission for this article to be further copied/distributed or hosted elsewhere without the express permission from The New Chaucer Society. 
NOT THE PUBLISHED VERSION; this is the author's final, peer-reviewed manuscript. The published version may be accessed by following the link in the citation at the bottom of the page.

Keenan, K., \& Wakschlag, L. S. (2002). Can a valid diagnosis of disruptive behavior disorder be made in preschool children? American Journal of Psychiatry, 159, 351-358.

Keller, K. M., \& Fox, R. A. (2009). Toddlers with developmental delays and challenging behaviors. Early Child Development and Care, 179, 87-92.

McDiarmid, M. D., \& Bagner, D. M. (2005). Parent-child interaction therapy for children with disruptive behavior and developmental disabilities. Education \& Treatment of Children, 28, 130-141.

McIntyre, L. L. (2008). Parent training for young children with developmental delays: Randomized controlled trial. American Journal on Mental Retardation, 113, 356-368.

McMahon, R. J., Wells, K. C., \& Kotler, J. S. (2006). Effectiveness of the Coping Power program and of classroom intervention with aggressive children: Outcome at a 1-year follow-up. Behavior Therapy, 34, 493515.

Mendez, J. L., Fantuzzo, J. \& Cicchetti, D. (2002). Profiles of social competence among low-income African American preschool children. Child Development, 73, 1085-1101.

Neilsen, S. L., \& McEvoy, M. A. (2004). Functional behavioral assessment in early education settings. Journal of Early Intervention, 26, 115-131.

Nicholson, B. C., Anderson, M., Fox, R. A., \& Brenner, V. (2002). One family at a time: A prevention program for at-risk parents. Journal of Counseling and Development, 80, 362-371.

Nicholson, B. C., Brenner, V., \& Fox, R. A. (1999). A community-based parenting program with Iow-income mothers of young children. Families in Society: The Journal of Contemporary Human Services, 80, 247-253.

Nicholson, B. C., Fox, R. A., \& Johnson, S. D. (2005). Parenting young children with challenging behaviour. Infant and Child Development, 14, 425-428.

Olson, S. L., Ceballo, R., \& Park, C. (2002). Early problem behavior among children from low-income, mother-headed families: A multiple risk perspective. Journal of Clinical Child and Adolescent Psychology, 31, 419-430.

Peters, C., \& Fox, R. A. (1993). Parenting Inventory: Validity and social desirability. Psychological Reports, 72, 683-689.

Qi, C. H., \& Kaiser, A. P. (2003). Behavior problems of preschool children from low- income families: Review of the literature. Topics in Early Childhood Special Education, 23, 188-216.

Richman, N., Stevenson, J., \& Graham, P. J. (1982). Preschool to school: $A$ behavioral study. London: Academic Press.

Roberts, C., Mazzucchelli, T., Studman, L., \& Sanders, M. R. (2006). Behavioral family interventions for children with developmental

Child \& Family Behavior Therapy, Vol. 31, No. 4 (November 2009): pg. 292-311. DOI. This article is (C) The New Chaucer Society and permission has been granted for this version to appear in e-Publications@Marquette. The New Chaucer Society does not grant permission for this article to be further copied/distributed or hosted elsewhere without the express permission from The New Chaucer Society. 
NOT THE PUBLISHED VERSION; this is the author's final, peer-reviewed manuscript. The published version may be accessed by following the link in the citation at the bottom of the page.

disabilities and behavioral problems. Journal of Clinical Child and Adolescent Psychology, 35, 180-193.

Roberts, C., Mazzucchelli, T., Taylor, K., \& Reid, R. (2003). Early intervention for behavior problems in young children with developmental disabilities. International Journal of Disability, Development, and Education, 50, 275-292.

Rodriquez, C. M., \& Murphy, L. E. (1997). Parenting stress and abuse potential in mothers of children with development disabilities. Child Maltreatment, 2, 245-251.

Rogers, S. J., \& D’Eugenio, D. B. (1981). Assessment and Application. Ann Arbor, MI; The University of Michigan Press.

Sanders, M. R. (1999). Triple P-Positive Parenting Program: Towards an empirically validated multilevel parenting and family support strategy for the prevention of behavior and emotional problems in children. Clinical Child \& Family Psychology Review, 2, 71-90.

Sanders, M. R., Mazzucchelli, T. G., \& Studman, L. J. (2004). Stepping Stones Triple P: The theoretical basis and development of an evidence-based positive parenting program for families with a child who has a disability. Journal of Intellectual and Developmental Disability, 29, 265-283.

Sigafoos, J. (2000). Communication development and aberrant behavior in children with developmental disabilities. Education and Training in Mental Retardation and Developmental Disabilities, 35, 168-176.

Snell-Johns, J., Mendez, J. L., \& Smith, B. H. (2004). Evidence based solutions for overcoming access barriers, decreasing attrition, and promoting change with underserved families. Journal of Family Psychology, 18, 19-35.

Sparrow, S. S., Balla, D. A., \& Cicchetti, D. (1984). Vineland Adaptive Behavior Scales. Bloomington, MN; Pearson Assessments.

Tucker, M. A., \& Fox, R. A. (1995). Assessment of families with mildly handicapped preschoolers. Journal of School Psychology, 33, 29-37.

Webster-Stratton, C. (1994). Advancing videotape parent training: A comparison study. Journal of Consulting and Clinical Psychology, 62, 583-593.

Webster-Stratton, C., Ried, M., \& Hammond, M. (2001). Preventing conduct problems, promoting social competence in Head Start children: Prevalence, pervasiveness, and associated risk factors. Clinical Child and Family Psychology Review, 1, 101-124.

Weis, R., Lovejoy, M. C., \& Lundahl, B. (2004). Factor structure and discriminative validity of the Eyberg Child Behavior Inventory with young children. Journal of Psychopathology and Behavioral Assessment, 27, 269-278.

Child \& Family Behavior Therapy, Vol. 31, No. 4 (November 2009): pg. 292-311. DOI. This article is (c) The New Chaucer Society and permission has been granted for this version to appear in e-Publications@Marquette. The New Chaucer Society does not grant permission for this article to be further copied/distributed or hosted elsewhere without the express permission from The New Chaucer Society. 
NOT THE PUBLISHED VERSION; this is the author's final, peer-reviewed manuscript. The published version may be accessed by following the link in the citation at the bottom of the page.

Table 1. Demographic Data for Delayed and Non-delayed Groups at Pre-Treatment

\begin{tabular}{|c|c|c|c|c|c|c|c|c|}
\hline \multirow[b]{2}{*}{ Variable } & \multicolumn{4}{|c|}{ Delayed $^{a}$} & \multicolumn{4}{|c|}{ Non-delayed ${ }^{b}$} \\
\hline & $M$ & $S D$ & $n$ & $\%$ & $M$ & $S D$ & $n$ & $\%$ \\
\hline Age of Child & 2.45 & .57 & & & 2.88 & .93 & & \\
\hline \multicolumn{9}{|l|}{ Gender } \\
\hline Female & & & 12 & 44 & & & 15 & 55 \\
\hline Male & & & 15 & 55 & & & 12 & 44 \\
\hline \multicolumn{9}{|l|}{ Race } \\
\hline African American & & & 12 & 44 & & & 12 & 44 \\
\hline Latino & & & 5 & 18 & & & 6 & 22 \\
\hline Caucasian & & & 6 & 22 & & & 5 & 19 \\
\hline Mixed Ethnicity & & & 3 & 11 & & & 4 & 14 \\
\hline Other & & & 1 & 4 & & & 0 & 0 \\
\hline Psychiatric Diagnosis & & & 19 & 70 & & & 21 & 78 \\
\hline \multicolumn{9}{|l|}{ Marital Status } \\
\hline Married & & & 11 & 41 & & & 10 & 37 \\
\hline Single & & & 16 & 59 & & & 17 & 63 \\
\hline \multicolumn{9}{|l|}{ Public Assistance } \\
\hline Yes & & & 22 & 81 & & & 20 & 74 \\
\hline No & & & 5 & 19 & & & 7 & 16 \\
\hline Years of Parent Education & 12.27 & 2.41 & & & 12.00 & 2.91 & & \\
\hline $\begin{array}{l}\text { Number of Children in } \\
\text { Home }\end{array}$ & 2.40 & 1.21 & & & 2.65 & 1.67 & & \\
\hline
\end{tabular}

Note: $a n=27 . b n=27$. Public Assistance $=$ family reported receiving government aid in form of insurance, food stamps, or other support. In order to receive government aid, total family income must fall below the federal poverty level. 
NOT THE PUBLISHED VERSION; this is the author's final, peer-reviewed manuscript. The published version may be accessed by following the link in the citation at the bottom of the page.

Table 2: Means and Standard Deviations by Group at Pre- and PostTreatment

\begin{tabular}{|c|c|c|c|c|c|c|c|c|c|}
\hline \multirow[b]{3}{*}{ Measure } & \multicolumn{4}{|c|}{ Delayed } & \multicolumn{5}{|c|}{ Non-delayed } \\
\hline & \multicolumn{2}{|c|}{ Pre-treatment } & \multicolumn{2}{|c|}{ Post-treatment } & \multicolumn{2}{|c|}{ Pre-treatment } & \multicolumn{3}{|c|}{ Post-treatment } \\
\hline & $M$ & $S D$ & $M$ & SD & $M$ & $S D$ & $M$ & $\overline{S D}$ & $n^{2}$ \\
\hline ECBI & & & & & & & & & 40 \\
\hline Intensity & 1321 & 39.1 & 1131 & 327 & 146.9 & 34.6 & 132.6 & 37.8 & 19 \\
\hline Problem & 17.38 & 7.47 & 9.35 & 7.95 & 17.1 & 7.45 & 11.41 & 10 & .33 \\
\hline Child Observation & 18.22 & 2.84 & 17.50 & 2.20 & 19.5 & 3.41 & 18.2 & 199 & .64 \\
\hline Positive Affect & 3.19 & 1.07 & 4.2 & 0.45 & 3.46 & 1,12 & 4.29 & 0.63 & 39 \\
\hline Negative Affect & 1.85 & 0.82 & 1.07 & 0.05 & 151 & 0.74 & 1,15 & 0.25 & 35 \\
\hline $\begin{array}{l}\text { Interest in Play } \\
\text { Initiates }\end{array}$ & 4.19 & 0.83 & 3.87 & 1.25 & 431 & 0.87 & 4.02 & 1.22 & .13 \\
\hline $\begin{array}{l}\text { Interaction } \\
\text { Socialy }\end{array}$ & 296 & 0.89 & 4.26 & 0.68 & 3.34 & 0.92 & 4.42 & 0.65 & \\
\hline Responsive & 373 & 0.9 & 4.09 & 0.9 & 388 & 0.8 & 2.35 & 0.65 & 35 \\
\hline PBC & & & & & & & & & .26 \\
\hline Expectations & 25.59 & 6.21 & 28,56 & 6.2 & 29.67 & 7.22 & 33.33 & 7.47 & .19 \\
\hline Discipline & 15,06 & 387 & 13.96 & 421 & 1666 & 7.47 & 14.04 & 587 & $0 \mathrm{~B}$ \\
\hline Nurturing & 29.71 & 4.75 & 31.22 & 5.37 & 29.71 & 4.75 & 32.07 & 6.67 & \\
\hline Parent Observation & 20.65 & 3.57 & 22.71 & 2.38 & 19.55 & 3.4 & 2297 & 1.83 & .68 \\
\hline Parent Leads & 3.37 & 0.97 & 2.81 & 106 & 38 & 0.96 & 2.8 & 1.19 & .20 \\
\hline Child Leads & 2.67 & 107 & 3.62 & 1.02 & 231 & 0.95 & 36 & 1.25 & 31 \\
\hline Sensitivity & 3.69 & 0.82 & 4.23 & 0.67 & 3.54 & 1 & 4.2 & 0.66 & \\
\hline Expectations & 3.56 & 1.15 & 4.27 & 0.63 & 329 & 0.98 & 4.17 & 0.75 & 31 \\
\hline Limit Setting & 3.93 & 1.24 & 4.21 & 09 & 3.13 & 1.47 & 437 & 0.58 & .02 \\
\hline Reciprocity & 3.48 & 109 & 4.16 & 0.88 & 361 & 0.88 & 4.49 & 0.53 & .38 \\
\hline Parent-Child Rx & 59 & 11.7 & 73.07 & 135 & 59 & 16.2 & 76.85 & 11.2 & 54 \\
\hline
\end{tabular}

Note. $n=27$ per group. $\eta 2$ statistic is provided for statistically significant (i.e., $p$ $<.05)$ pre-post treatment changes.

\section{Table 3: Percentage of families exceeding RCI for study's outcome measures from Pre- to Post-Treatment}

\begin{tabular}{llll} 
Measure & Delayed & Non-delayed & $\begin{array}{l}\text { Significant difference } \\
\text { between groups }\end{array}$ \\
\hline ECBI Intensity & 15 & 30 & \\
ECBI Problem & 41 & 30 & \\
PBC Discipline & 22 & 48 & $\chi^{2}(1,54)=3.98, p<.05$ \\
PBC Nurturing & 11 & 26 & \\
PBC Expectations & 17 & 55 & $\chi^{2}(1,54)=10.68, p<.01$ \\
Parent-Child Relationship Scale & 74 & 30 & \\
Direct Observation & & & \\
$\quad$ Child Factors & 7 & 11 & \\
$\quad$ Parent Factors & 33 & 37 & \\
\hline
\end{tabular}

Note: The values represent percentages.

Child \& Family Behavior Therapy, Vol. 31, No. 4 (November 2009): pg. 292-311. DOI. This article is (c) The New Chaucer Society and permission has been granted for this version to appear in e-Publications@Marquette. The New Chaucer Society does not grant permission for this article to be further copied/distributed or hosted elsewhere without the express permission from The New Chaucer Society. 